till it appears in the cleft; and, to complete the separation, an aneurism needle can be conveniently employed from within the cleft so as to meet the raspatory, which latter can be withdrawn. At the point where the hard and the soft palate unite, the flaps are always firmly attached by a process of fascia to the posterior margin of the bony palate. The separation at this spot can only be satisfactorily effected by a cutting instrument, and for this purpose a pair of short-bladed angular scissors is useful. One blade is passed under the flap between it and the bone, and the other through the cleft over the nasal surface of the palate. This includes the fascia, and entirely frees the flaps. The sutures are inserted with the tubular needle, and managed in a precisely similar way as in the soft palate. They may, however, in some cases be allowed to remain in a few weeks longer with advantage. In highly arched palates, the flaps are often redundant, the margin being readily approximated; while in broad and flat palates, the incisions for the raspatory will need free extension, both backwards and forwards, leavins an elliptical gap of considerable width on each side. In carrying the incision backwards, care must be taken to avoid the neighbourhood of the posterior palatine canal, or troublesome hæmorrhage may ensue. In cases of complete cleft with harelip, I think an advantage is gained by closing the soft palate first, and in a few weeks' time, operating upon the lip. The latter having been cured, the margins of the cleft in front and the alveolar process come together with comparative rapidity. It is desirable, however, to defer closing the hard palate for some months. With regard to the after-treatment, nothing very special is required. It is by no means necessary for the patient to remain in bed beyond a few days. The diet should consist of fluid and unstimulating food, and, for the first week, principally milk. Afterwards, more solid food, provided it be made soft, may be freely allowed. After these operations, I prefer the patient having moderately warm, rather than iced drinks, be lieving that harm may possibly result from the latter being persisted in. I follow Mr. Smith's judicious advice, and refrain from inspecting the palate for the first few days after operations. The sutures should not be interfered with for at least two or three weeks, after which they can be readily removed, all sensitiveness having passed away.

I append a brief outline of a few cases which have been under my charge at the Liverpool Infirmary for Children. On each occasion, chloroform was the anæsthetic employed.

CASE I. Cleft of the Velum and of the Posterior Third of the Hard Palate.-Milly P., aged 3, an apparently healthy but really delicate child. On August 28th, I877, I closed the whole cleft, using silver wire and silk sutures alternately. The raspatory was employed to free the flaps from the bony palate. The margins of the cleft came together without tension. On the fourth day, I found that union had failed. The edges looked unhealthy, and the entire palate was in a very inflamed condition. Convalescence was retarded by troublesome diarrhœa.

CASE II.-Cleft of the Velum and one-third of the Hard Palate.Alice L., aged 7. On January I9th, 1878, I closed the soft palate only, adopting Mr. Pollock's method of paralysing muscular action, and using silk sutures, except at the base of the uvula and at a point in the cleft as far forwards as the margins could be brought together, where I substituted silver wire. On the fifth day, all had well united; but on the sixth, the silk sutures appeared to be causing so much irritation that I considered it desirable to remove them. In doing so, the union of the uvula gave way up to the silver suture. At the end of the third week, the two silver stitches were removed, all the soft palate brought together being firmly united, the uvula excepted. On October 26th, I closed the foramen, which in the meantime had considerably diminished in size, with three silver wire sutures, making lateral incisions and using the raspatory. On inspection, a few days afterwards, the foramen was found to be quite closed. On November r6th, I united the bifid uvula, using very fine silver sutures. The result was quite satisfactory, the whole of the cleft being now completely closed. There is well marked improvement in the child's articulation since the first operation.

CASE III. Cleft of the Velum and Hard Paiate up to the Intermaxillary Bonc.- Michael B., aged 3, a healthy child, had a cleft of considerable width; but the mouth was peculiarly small. On March 23rd, I 878 , I closed the velum as far forwards as I could without tension, using silver wire for all the sutures except the upper two, which were of fishing-gut. I adopted Mr. Pollock's incisions, and divided the pillars of the fauces. On the fifth day, it was found that union had taken place where the silver wire was used, but the gut sutures had ulcerated out. A very serviceable soft palate was the result. On September 14th, I closed the hard palate, except the extreme anterior angle, carrying the incisions for the raspatory well back, as the cleft was a wide one. On the fourth day, union appeared to have taken place; but on the evening of the fifth, hæmorrhage came on, which soon ceased without interference. On inspection, a few days later, I found that the palate had remained closed, leaving, however, two small foramina. On the child's readmission, a mild 'attack of scarlet fever prevented an attempt from being made to close these foramina, and he has not been brought to the Infirmary since.

CASE Iv. Cleft of the Velum and the Posterior Half of the Hard Palate.-William B., aged 3. On admission, the child was healthy, but had an irritable cough, and the operation was deferred until this was better. On September 2rst, I878, I closed the whole cleft, following Mr. Pollock's method of restraining muscular action, and making lateral incisions parallel to the margins of the cleft, through the upper part of the soft palate and through the muco-periosteum of the palatine portion, freeing the flaps with the raspatory. I used silver wire sutures. The margins of the cleft came fairly well together; but. unfortunately, next day the cough returned. On examination, a few days later, I found the soft palate had given way, but nearly all the hard had united. On November 2nd, I made a second attempt to close the velum, or rather the lower two-thirds of it, again adopting Mr. Pollock's incisions, and on this occasion dividing the pillars of the fauces. Silver wire was employed for sutures. The foramen thus formed was nearly circular, and over half-an-inch in diameter. The result of this operation was quite successful. On October I Ith, I879, I closed the foramen, which at this time appeared as a mere slit a quarter of an inch in length, and the edges even touching.

CASE V.-Cleft of the Velum and half-an-inch of the Hard Palate, with Harelip which had been closed in Infancy.- - Harold S., Aged 3, a rather delicate child from the country. On August 24th, 1878, I closed the velum to within a quarter of an inch of the bony fissure with fine silver wire. No muscles were divided nor were any incisions made. It united perfectly, and the sutures were removed at the end of the third week. On April 24th, 1879, I closed the foramen with three silver sutures, making lateral incisions and using the raspatory. The cleft in the palate is now completely cured, but on the left side there is a small hole, the result of an accidental tear made by the raspatory; this can be closed at any time.

CASE Vi.-Complete Cleft of Hard and Soft Palate, and of the Right Lit and Nostril. - William C., aged I I, first came under my notice, suffering from vesical calculi; and lithotomy being performed, two moderately large stones were extracted. After convalescence, he returned home for a few weeks. On November I6th, 1878, I closed the cleft in the velum, following Mr. Pollock's plan of incising the palate. Silver wire was used for sutures. The fact of the hare-lip existing greatly facilitated the operation, allowing ample light and room to work in. The result was quite satisfactory; and on the twenty-first day, the sutures were removed. On December 4 th, I closed the hare-lip without interfering with the alveolar process in any way, well freeing the soft structures on each side from their bony attachments. The cure of the lip was satisfactory. The boy returned home for five months; and on May roth, 1879, I closed the hard palate. The cleft in the alveolar process had meanwhile closed spontaneously; before the hare-lip was operated upon, it was fully half-an-inch wide. The sutures were removed at the end of the fifth week. All the palate is now closed, except two small holes; one at the point where the hard and the soft palate meet, the other at the anterior angle behind the alveolar process. The articulation, which previo sly to closing the fissure was absolutely unintelligible, is now very considerably improved.

\section{THE TREATMENT OF ASTHMA}

By J. B. BERKART, M.D.,

Senior Assistant-Physician to the City of London Hospital, etc.

\section{I.}

From the earliest days of the history of medicine until the present moment, narcotics, antispasmodics, et hoc genus omne, have been, severally or in endless combinations, and with no sparing hand, applied to every orifice of the body for the purpose of subduing the nervous irritability supposed to be the essence, or at least the chief element, of asthma; and yet, notwithstanding the indubitable efficacy of these remedies, the records of medicine contain not one single instance in which that practice has produced, at best, a more than temporary benefit. Enthusiastic therapeutists, it is true, allege that in some cases antispasmodic fumes, a certain mixture taken three times a day, and a certain pill at night, have led to the happiest results; but the remark they add, that the patients had to carry about with them their panacea, to be used with every recurrent attack, somewhat obscures the brilliancy of their success. The bulk of practitioners have been less fortunate in their experience as regards relief or cure of asthma; and their opinion that this is the most intractable of all diseases is unhappily in strict accordance with facts.

No sadder impression can be received than by studying what is still 
current for the pathology of asthma. Not only in science, but in the ordinary business of life, if a given conclusion prove faulty, the rule prevails to seek the source of error by examining the propositions; but, in the case of asthma, this elementary principle of reasoning has been persistently neglected. Here experience has shown that a certain treatment, consisting in the administration of the most potent remedies, does not produce the expected effect. Instead of inquiring into the principles upon which that treatment is based, the question is shelved by assuming a "double capriciousness" of the disease as the cause of failure. But this is not all : the commonest matter of fact in relation to asthma is mystified and perverted. If a dyspeptic suffer after a heavy meal from flatulence and dyspnœa, the fruit or cheese with which the repast was finished is considered a "highly asthmatic article". If dust inhaled at the seaside impede respiration, "the air of Margate is unsuitable". And not the least painful matter is that, if facts and arguments be adduced to show the puerility of such reasoning, they are met by an unanswerable "I believe". If medicine were an abstract science, one might smile at such process of reasoning; but where, as in medicine, every theory even unconsciously influences practice, the utter want of logical thought must have the most pernicious consequences. If proof of this were needed, I would point to the innumerable instances which yesterday were considered to be, and treated as, "purely spasmodic asthma", but which to-day present themselves as hopelessly incurable phthisis. If further proof were needed, there is the practical outcome of the prevailing theory, as shown by the advice of Hyde Salter: "Give it a shake; make some change, any change, no matter whether the object is very definite or the therapeutics very rational......the most blind and purposeless treatment may be attended with the happiest results" (On Asthma, etc., 2nd ed., p. IO4).

The fact is, asthma must remain a stigma on medical science, and the lucrative pursuit of speculative druggists, until its pathology is correctly understood. That the subject is somewhat obscure will be readily admitted; but what obscurities there are may be readily removed. It will be remembered that when, at the commencement of the present century, the systems of medicine were swept away, the diagnosis of cardiac and pulmonary affections was established upon the study of "physical signs" during life, and upon the changes in the organs as observed after death. Only one "essential" disease was admitted upon the absence of these criteria, and that disease was "asthma". I will not now repeat what I have elsewhere stated ad nauseam. At present, I only venture to remark that, if the physical signs of asthma were as broadly significant as those of certain forms of pneumonia and of pleurisy, a well-trained nurse could readily replace the physician. The superiority of the latter consists, according to my mind, in his power of observing facts, in interpreting and comparing them, and in arriving in this way at the hidden truth.

Nothing, I repeat, but the correct knowledge of the pathology of asthma shows the means of speedily and safely relieving the paroxysms, and of preventing their recurrence. It alone guards against the indiscriminate administration of the most useful remedies; for, unless they be given in suitable circumstances, in sufficiently large doses, etc., the benefit they are capable of producing is unattainable.

It lies in the nature of asthma that the treatment of the paroxysms should be paramount. No one who has ever witnessed an asthmatic seizure would for a moment hesitate to relieve the patient by any means in his power ; and, however repugnant it must be to use preparations of unknown composition and of unknown action-as are the various specifics recommended in newspapers-even their exhibition would be willingly connived at, provided there were no rational means for the attainment of the same end. But no specifics are needed. The remedies in general use suffice for every contingency. Of course, the ideally perfect treatment would be to apply such remedies as, by removing the urgent symptoms, would exert at the same time a favourable influence upon the disease itself. Unfortunately, the most reliable remedies in use are of so slow operation as to be practically useless during the paroxysm, because the patient cannot or will not submit to measures which do not afford immediate benefit. Only one remedy-jaborandi and its alkaloid pilocarpin-approaches more nearly than any other the above requirement.

The powerful revolution which pilocarpin produces in the distribution of the blood must necessarily have a very beneficent influence in some forms of asthma; for, by attracting a large volume of blood to the skin and to the salivary glands, and by diminishing its volume through the copious perspiration and salivation, the congested internal organs are relieved in a corresponding degree. An adequate conception of the pathological changes in the lungs, indicating the use of pilocarpin, may be formed by observing an analogous process in the lower extremities. In connection with varicosities, the leg at one time increases in circumference, the pale and dry tissues presenting a peculiar inelastic and spongy feel; at another, the enlarged leg has a dark brown colour, and its tissues are apparently indurated ; at another, in these circumstances, an ulcer developes itself. Mutatis mutandis, the same takes place in the lungs; only the interstitial changes in the lungs -in origin, in nature, and in progress precisely similar to those observed in the legs-are not amenable to diagnosis, unless they perceptibly diminish the volume of air, or interfere with its entrance or exit to and from the lungs by implicating the bronchi. Here then, pilocarpin has the same effect as the bandages in varicosities of the extremities. Within a few minutes, the application of the drug is followed not merely by amelioration of the subjective symptoms, but by a corresponding improvement of the physical signs. Of course, a remedy that so powerfully exalts one function necessarily depresses another, and therefore its use requires some caution. But with a little attention the remedy can be safely and successfully managed. I have found the alkaloid preferable to the plant because : 1 . it acts more rapidly; 2 , it does not produce strangury; and 3 , the dose can be more accurately determined.

Those whose cardiac muscles are from whatever causes in a state of fatty degeneration, may, under the influence of pilocarpin, present the most alarming symptoms. However, the cause for alarm soon spontaneously subsides, the heart regaining its previous force; but if it lingered to do so, a subcutaneous injection of $\mathbf{I}-\mathbf{I} 20$ th or $\mathbf{I}-60$ th grain of atropine immediately restores the balance. Pilocarpin is more suitable in the treatment of the younger asthmatics, but is by no means contraindicated in patients of more advanced age. The dose should not exceed one-third of a grain. I have never used more than ten drops of a two-per-cent. solution. During the action of the drug, the patient should preserve the recumbent posture-which the almost immediate relief obtained will enable him to do-and he should be carefully watched until the effect has passed off. It is desirable to have a solution of atropine always at hand, in case of need. It is well, also, not to use pilocarpin soon after the patient's meals ; if the dyspnceal seizure occur under these circumstances, there are, it is needless to say, other remedies more suitable.

The following case will show the immediate and the remote effects of pilocarpin.

CASE I.-J. C., aged 63, retired employé of the Fire Brigade, applied at Victoria Park Hospital on March 6th, 1879, complaining of dyspnœea with nocturnal exacerbation, so that he had been forced to spend the nights in his chair. He was of temperate habits. He became, six or seven years ago, subject to cough, from which he had suffered since. The expectoration was not copious, and consisted of a few hard lumps. $\mathrm{He}$ was of middle height, somewhat obese, with pale face, strong bones, muscular; was evidently suffering from dyspnœa. Tongue clean. Respirations 30. Pulse 80 , regular, and of slight tension. No increased temperature. Thorax wide; the movements were equal on both sides; the lungs were distended. Resonance in the right front and back was diminished, and there was absence of respiration; the left front and back were superresonant, whistling sounds were heard at the apex, and coarse rhonchi at the base. The heart was covered; its sounds were feebly audible, but clear.

3.7 P.M. Ten drops of two per cent. solution of pilocarpin were injected.

3. IO P.M. Perspiration commenced at the forehead.

3. 12 P.M. Salivation commenced.

3.13 P.M. Pulse 94-96. He felt his breathing much easier. $\mathrm{He}$ perspired freely; slight salivation.

3.24 P.M. A sphygmographic tracing was taken. Perspiration persisted. He felt easier ; could lay down.

3.30 P.M. He felt easier; respiration quite free, 28. The whistling at the left apex was replaced by subcrepitant râles, and, instead of the complete silence on the right side, there was now normal inspiration and expiration.

3.45 P.M. Observation was continued by Mr. Lund (the clinical clerk). The pupils acted to light; he expectorated whitish phlegm; breath easier; the whole of the body perspired; his face was flushed. Pulse 88 ; respirations 28 .

3.50 P.M. The cardiac action quite regular; there was very little salivation. Breath easy. Pulse 98.

4.3 P.M. Breathing was quite free; he felt much better; his whole body was in a glow, but he did not feel thirsty. Pulse 98 ; respirations 32 .

4. IO P.M. Perspiration stopped. Breathing was quite easy; the râles at the left base were considerably diminished in number and intensity; at the right base behind, slight subcrepitant rhonchi were heard. He felt better every way; and left the hospital. He was ordered to take an ounce of aqua menthæ piperitæ three times a-day, ut aliquid fiat.

J. C. attended for five successive weeks, and declared himself improved. He could now lie down and sleep at night. He still coughed, but expectoration was easier than it formerly had been.

[To be continued.] 